\title{
Acquisition of a "Group A"-Selective Src Kinase Inhibitor via A Global Targeting Strategy
}

\author{
Jung-Mi Hah, Vyas Sharma, Haishan Li, and David S. Lawrence \\ Department of Biochemistry, The Albert Einstein College of Medicine of Yeshiva University, 1300 \\ Morris Park Ave., Bronx, New York 10461
}

\section{Abstract}

A "global" strategy for the acquisition of selective high affinity inhibitors for the Src kinase subfamily of tyrosine kinases is described. Members of the Src family exhibit a strong amino acid sequence homology. However, recent studies have revealed differences in the relative spatial relationships of the three distinct protein-binding domains present in these enzymes. We have constructed an inhibitor, using an amalgamation of combinatorial methods and directed design, which simultaneously associates with the active site and an ancillary protein-binding region ( $\mathrm{SH} 2$ domain). The inhibitor exhibits high inhibitory potency and selectivity for the Group A versus Group B subset of Src kinases.

Protein tyrosine kinases (PTKs) catalyze the phosphorylation of tyrosine residues in proteins and synthetic peptides. PTKs are commonly segregated into subgroups on the basis of sequence homology, such as the Src subfamily, which is comprised of Blk, Fgr, Fyn, Hck, Lck, Lyn, Yes, Yrk, and Src. The latter are multidomain enzymes containing SH1 (catalytic core), SH2 (binds to phosphotyrosine-containing sequences) and SH3 (binds to proline-rich sequences)

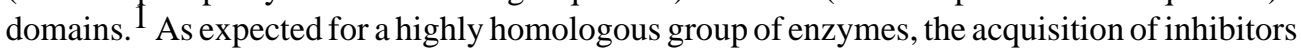
that selectively target individual Src PTKs has proven quite difficult. Selective agents not only have potential clinical implications, but also are essential for elucidating the biological roles of their enzyme targets. For example, Lck and Fyn are the Src kinase family participants in the signaling pathways that drive $\mathrm{T}$ cell activation. ${ }^{2}$ Although it had been presumed that these enzymes perform similar functions, it is now evident that these presumptions were mistaken and simply a consequence of experimental methods. ${ }^{2}$ A selective inhibitor for either of these PTKs could resolve many of the unanswered questions concerning the biochemical contributions of Fyn and/or Lck to T cell signaling. We report herein a combinatorial library/ multidomain targeting approach that has resulted in the identification of one of the most potent peptide-derived inhibitors ever devised for a PTK.

Although the overall structural organization, as well as the $\mathrm{SH} 1, \mathrm{SH} 2$, and $\mathrm{SH} 3$ domains, are very similar among all Src kinase family members, specific differences do exist that appear to have global structural ramifications. A recent study demonstrated that the relative orientation of the Lck SH2-SH3 domain pair differs from that of its counterpart in Fyn. ${ }^{3}$ Furthermore, disparities in the linker between the $\mathrm{SH} 1$ and $\mathrm{SH} 2$ domains appear to be responsible for relative domain displacements as well. ${ }^{4}$ Indeed, the latter differences in SH2 linker sequences correlate with the division of the Src kinase family into two separate subgroups (Group A: Fyn, Fgr, Src, and Yes; Group B: Blk, Hck, Lck, and Lyn). ${ }^{4}$ This suggests that it might be possible to differentiate between Group A (e.g. Fyn) and Group B (e.g. Lck) PTKs on the basis of differences in the spatial orientation of the SH domains. In short, inhibitors that simultaneously 
associate with two SH domains could conceivably exhibit a high degree of selectivity. Although Src kinase multidomain-directed "bivalent inhibitors" have been previously described, these species were composed of a low affinity active-site-directed peptide $\left(I C_{50}=1.6 \mathrm{mM}\right)$ coupled to a higher affinity SH2 domain-targeted sequence $\left(K_{\mathrm{D}}=1.3 \mu \mathrm{M}\right)$ in order to create a significantly better inhibitor $\left(I C_{50}=13 \mu \mathrm{M}\right) .{ }^{5}$ We reasoned that a more ideal strategy, in terms of acquiring a selective inhibitor, would employ two "energetically balanced" ligands (Fig. 1) that display approximately equal affinities for their respective domains. Under these circumstances, the enzyme affinity of the coupled bivalent inhibitor should significantly exceed that of the individual components alone. ${ }^{6}$

Active site (SH1)-directed peptides of PTKs are generally very poor inhibitors. ${ }^{7}$ For example, peptide 1 (Table 1), which is derived from the Src kinase consensus phosphorylation sequence, exhibits an $I C_{50}$ value of $380 \pm 80 \mu \mathrm{M}$. We previously reported a synthetic strategy that converts weak consensus sequence peptides into higher affinity ligands. ${ }^{8}$ We sought to transform 1 into an inhibitory agent whose affinity for the Src kinase active site is similar to that displayed by the SH2 domain targeting sequence Ac-pYEEIE $\left(I C_{50}=2.0 \mu \mathrm{M}^{9}\right)$ and then fuse these two sequences together. The consensus peptide 2 was prepared via solid phase peptide synthesis utilizing a disulfide-derivatized TentaGel resin (Scheme 1). The peptide-resin $\mathbf{2}$ was subsequently distributed, in equal amounts, into individual wells of multiwell synthesis plates. Each well contained one of 720 different carboxylic acids varying in size, shape, electrostatics, and hydrophobicity. Following coupling of the carboxylic acid library to the $\mathrm{N}$-terminus, the peptides were side chain-deprotected and cleaved from the resin with assay buffer (dithiothreitol) to furnish the primary library 3 (Scheme 1). An ELISA-based screen (Supporting Information) using the prototypical Group A Src kinase furnished the lead derivative possessing a substituted 3-methoxy-4-nitrobenzoic acid (Ba) substituent at the $\mathrm{N}$ terminus. The latter peptide was resynthesized with a C-terminal (L)-2,3-diaminopropionic acid (Dap) moiety (Scheme 1) and its inhibitory efficacy evaluated. Compound $\mathbf{4}$ is approximately an order of magnitude more potent than the parent peptide 1 (Table 1).

With the Ba-derivatized analogue 4 in hand, a secondary library 6 was prepared which contains the biasing Ba substituent at the N-terminus and molecular diversity incorporated onto the Dap side chain amine at the $\mathrm{C}$-terminus (Scheme 1). The hexachloronorborenyl acid (Hna)substituted lead 7 exhibits a nearly 200 -fold lower $I C_{50}(1.9 \pm 0.3 \mu \mathrm{M})$ than peptide $\mathbf{1}$ (Table 1). The apparent active site affinity of inhibitor 7 closely approximates the apparent $\mathrm{SH} 2$ affinity $\left(I C_{50}=2 \mu \mathrm{M}\right)$ of Ac-pYEEIE. The $I C_{50}$ values of 7 are not affected by simultaneous occupancy of the SH2 domain by an SH2 domain ligand (Supporting Information). Interestingly, peptide 7 does exhibit modest selectivity (2 - 17-fold) in favor of Group A enzymes (Supporting Information).

Although the 3-dimensional structures of both inactive and active forms of full-length Src kinases are known, these enzymes have not yet been successfully crystallized bearing bound peptides. ${ }^{2}$ Consequently, the relative orientation and distance between individual peptides separately associated with the active site and $\mathrm{SH} 2$ domain are not known. With this uncertainty in mind, we decided to synthesize a small library of multidomain-targeting peptides in which the active site-directed compound $\mathbf{7}$ is linked to its SH2-targeted counterpart, pYEEIE, via a variable length tether. The synthetic protocol illustrated in Scheme 2 furnished the peptide series 11 - 16, whose members differ only in the number of ßAla residues comprising the linker region. The length of the ßAla-containing tether has a profound impact on inhibitory potency. Compound 13 ( 3 BAla residues) is the most effective derivative in the bivalent series, exhibiting an $I C_{50}$ of $36 \pm 2 \mathrm{nM}\left(K_{\mathrm{i}}=26 \pm 4 \mathrm{nM}\right)$ approximately four orders of magnitude better than the parent peptide 1 . 
The bivalent inhibitor 13 displays several intriguing properties. First, as noted above, the potency of the vast majority of peptidic inhibitors of Src and related enzymes is extraordinarily poor. By contrast, compound $\mathbf{1 3}$ is, to the best of our knowledge, one of the most potent peptidebased, active site-directed, PTK inhibitors ever described. ${ }^{10}$ Second, the BAla tether length is extremely short, suggesting that the $\mathrm{SH} 2$ and active site regions assume an essentially contiguous spatial arrangement when both sites are concurrently occupied. Third, compound $\mathbf{1 3}$ simultaneously targets two functionally distinct regions on the Src kinase, whereas simple monovalent ligands can either block enzymatic activity (active site-directed) or signaling complex formation (SH2 domain-directed), but not both. Finally, 13 exhibits up to a 1600-fold selectivity in favor of Group A [Fyn $\left(I C_{50}=53 \pm 4 \mathrm{nM}\right), \operatorname{Fgr}(180 \pm 40 \mathrm{nM}), \operatorname{Src}(36 \pm 2 \mathrm{nM})$, Yes $(27 \pm 3 \mathrm{nM})]$ versus Group B [Blk $(2.6 \pm 0.7 \mu \mathrm{M})$, Hck $(2.3 \pm 0.7 \mu \mathrm{M})$, Lck $(43 \pm 4 \mu \mathrm{M})$, Lyn $(2.6 \pm 0.8 \mu \mathrm{M})]$ enzymes. The 900 -fold selectivity of $\mathbf{1 3}$ for Fyn versus Lck should prove useful in disentangling the overlapping roles played by these enzymes in $\mathrm{T}$ cell activation.

\section{Supplementary Material}

Refer to Web version on PubMed Central for supplementary material.

\section{ACKNOWLEDGMENT}

This work was supported by the National Institutes of Health. We thank Mr. Sean Cahill and Dr. Michael Blumenstein for assistance with NMR data acquisition and interpretation.

\section{REFERENCES}

1. Boggon TJ, Eck MJ. Oncogene 2004;23:7918-7927. [PubMed: 15489910]

2. Palacios EH, Weiss A. Oncogene 2004;23:7990-8000. [PubMed: 15489916]

3. Hofmann G, Schweimer K, Kiessling A, Hofinger E, Bauer F, Hoffmann S, Rosch P, Campbell ID, Werner JM, Sticht H. Biochemistry 2005;44:13043-13050. [PubMed: 16185072]

4. Williams JC, Wierenga RK, Saraste M. Trends Biochem Sci 1998;23:179-84. [PubMed: 9612082]

5. Profit AA, Lee TR, Niu J, Lawrence DS. J Biol Chem 2001;276:9446-51. [PubMed: 11118446]

6. Jencks WP. Proc. Natl. Acad. Sci. USA 1981;78:4046-4050. [PubMed: 16593049]

7. Lawrence DS, Niu J. Pharmacol. Therap 1998;77:81-114. [PubMed: 9578319]

8. Li H, Lawrence DS. Chem. Biol 2005;12:905-912. [PubMed: 16125102] and references cited therein.

9. Park S-H, Won J, Lee K-H. Bioorg. Med. Chem. Lett 2002;12:2711-4. [PubMed: 12217360]

10(a). See two alternative strategies that have delivered potent peptide-based inhibitors for Src kinase family members:Alfaro-Lopez J, Yuan W, Phan BC, Kamath J, Lou Q, Lam KS, Hruby VJ. J. Med. Chem 1998;41:2252-60. [PubMed: 9632358] (b) Parang K, Till JH, Ablooglu AJ, Kohanski RA, Hubbard SR, Cole PA. Nat. Struct. Biol 2001;8:37-41. [PubMed: 11135668] 

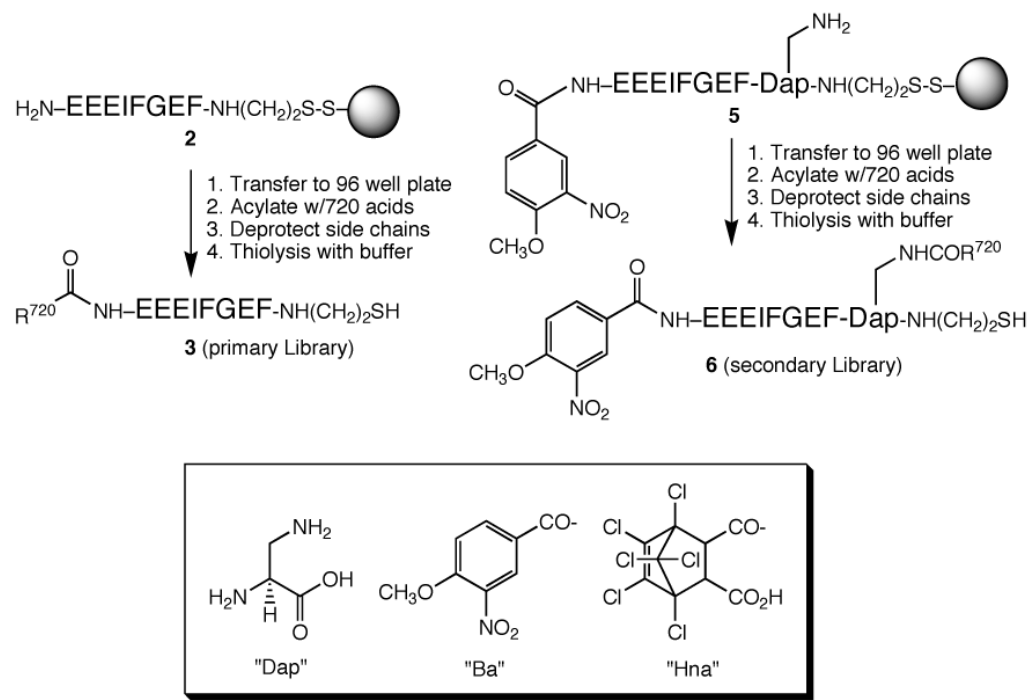

Scheme 1.

Two step synthetic protocol for the preparation of the low $\mu \mathrm{M}$ affinity SH1 domain-targeting inhibitor 7 (Table 1). 


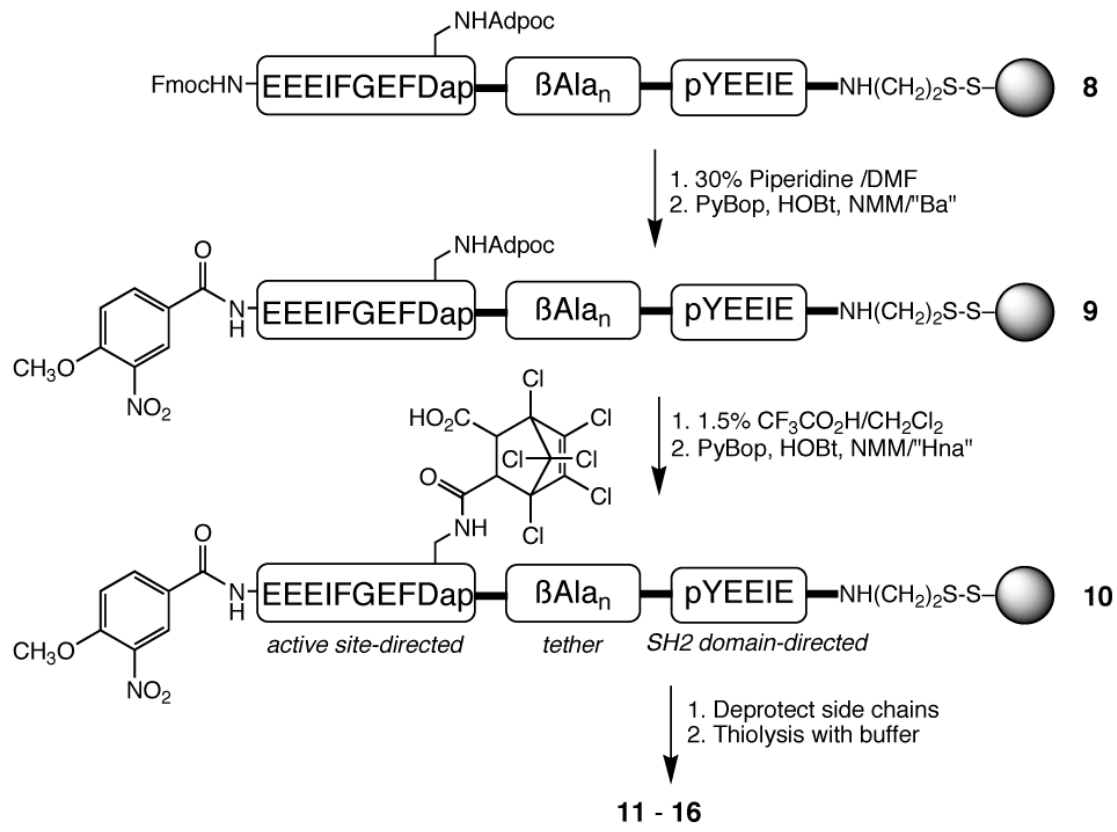

Scheme 2.

Preparation of Bivalent Inhibitors 11-16. 


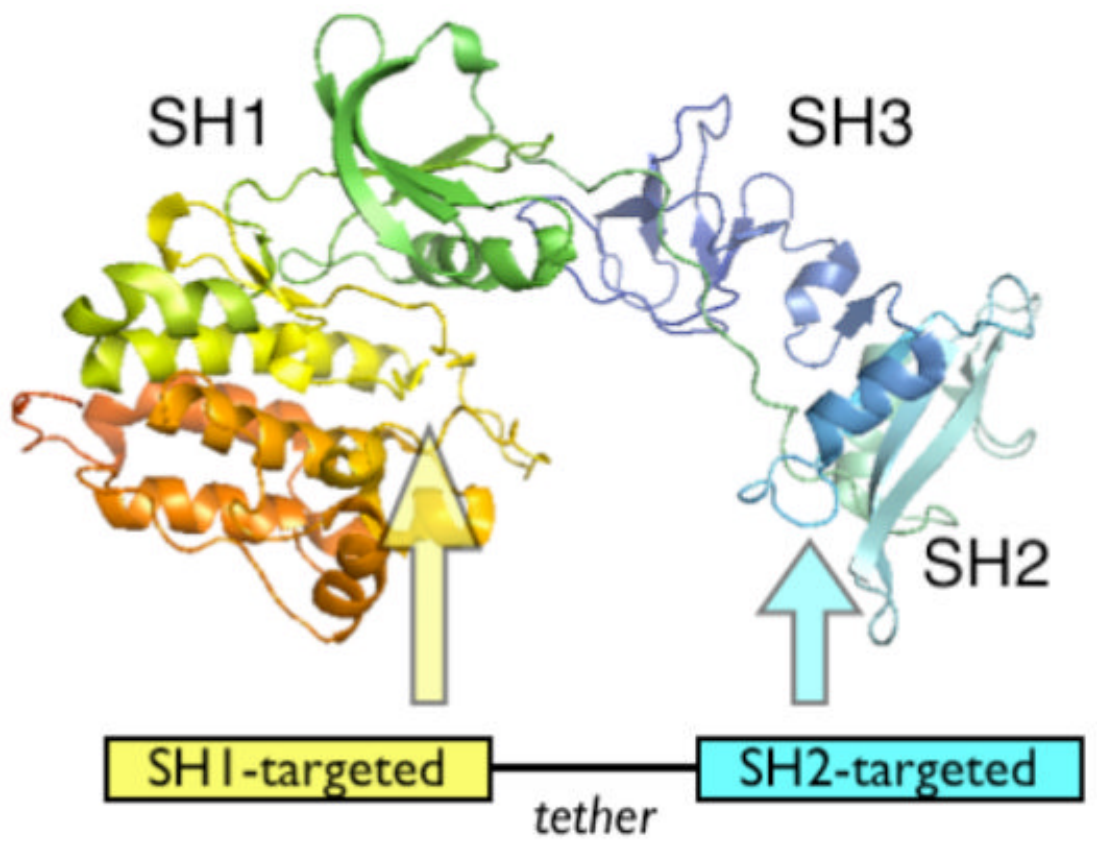

Figure 1.

Two-domain-targeting inhibitor for the Src kinase family. The individual SH1- and SH2targeting sequences are designed to have approximately equal affinities for their respective domains. 
Table 1

Src Kinase Inhibitors

\begin{tabular}{|c|c|}
\hline Inhibitor Structure & $I C_{50}(\mu \mathrm{M})$ \\
\hline 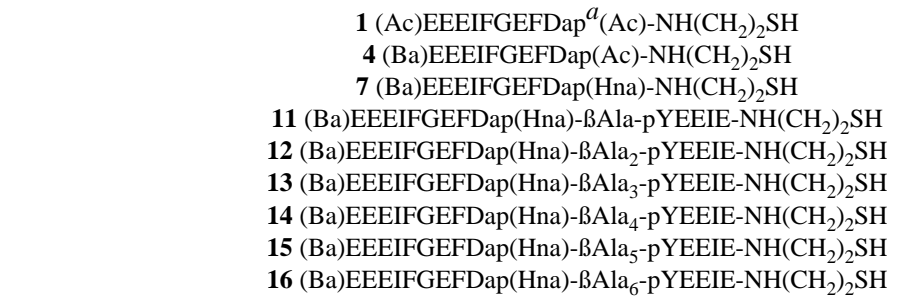 & $\begin{aligned} 380 & \pm 80 \\
32 & \pm 3 \\
1.9 & \pm 0.3 \\
3.8 & \pm 0.2 \\
0.24 & \pm 0.04 \\
0.04 & \pm 0.01 \\
0.06 & \pm 0.01 \\
0.16 & \pm 0.02 \\
0.21 & \pm 0.07\end{aligned}$ \\
\hline
\end{tabular}

